\title{
Further Pharmacological Studies Using the Compound (1z)-2-(Hydroxymethyl)-Dodec-1-Ene-1,3-Diol
}

\author{
Mona M. Al-Dawsary ${ }^{1}$ and Kamal E. H. El Tahir ${ }^{2}$ \\ 1. Department of Biology, University of Salman bin Abdel Aziz, Al Kharj 11942, Saudi Arabia \\ 2. Department of Pharmacology, King Saud University, Riyadh 12372, Saudi Arabia
}

\begin{abstract}
The compound (1z)-2-(hydroxymethyl)-dodec-1-ene-1,3-diol was previously isolated from the integument of the red palm weevil Rhynhophorus ferruginous and found to antagonize calcium chloride induced dysrrhythmia in mice. Further calcium-dependent pharmacological actions performed in this study revealed that it has the ability to inhibit platelets aggregation induced in guinea pigs with either ADP or archegonia acids, and the compound also decreased the arterial pressure in rats in a dose-dependent manner and exerted potential ant consultant activity in mice against pentylene tetrazole-induced seizures. However, no complete protection was observed. Analgesic studies in mice using the hot plate $\left(58^{\circ} \mathrm{C}\right)$ revealed its potential analgesic activities. Its effective dose 50 (ED50) was $85.7 \pm 6.3 \mathrm{mg} / \mathrm{kg}(N=5)$. The compound seamed to produce all of the above actions via a calcium antagonistic action.
\end{abstract}

Key words: (1z)-2-(hydroxymethyl) dodec-1-ene-1,3-diol, mice, $R$. ferruginous.

\section{Introduction}

Since the existence of man in this word, he started to search his environment for supplies of food and drugs. Every natural product whether it was a plant, an animal or a mineral was examined. Many natural drugs have been discovered through this way. In recent years, interest was aroused in insects as a source of drugs. A few years ago, we screened various extracts of the red palm weevil $R$. ferruginous for any pharmacological actions. This led to the discovery that the integument extracts contain a cardio protective agent and further research reveals its chemical identity.

(1z)-2-(hydroxymethyl)-dodec-l-ene-1,3-diol, the compound seemed to induce its cardiac profective effects in mice via antagorism to calcium [1, 2]. It was then thought of interest to continue searching for further pharmacological actions to characterize the spectrum of this compound. This paper studies the

Corresponding author: Mona Mohammed Saleh Al-Dawsary, Ph.D., research fields: insects physiology, sense organs and pharmacology. E-mail: wisdom1425@yahoo.com. influence of the compound and many pharmacological actions that depend exclusively on the availability of normal intracellular calcium ions (Ca2+) concentration. In this paper, some of those actions such as platelets aggregation [3, 4], the arterial good pressure are also included [5-10].

\section{Methods}

\subsection{Experimental Animals}

All of the animals (rats, mice and guinea-pigs) used in this study were provided by the Experimental Animal Care Center, College of Pharmacy, King saud University, Riyadh, Kingdom of Saudi Arabia. All of the animals were maintained at a temperature of $22 \pm$ $2{ }^{\circ} \mathrm{C}$ and relative humidity of $5 \pm 5 \%$ ). The light dark cycle was set at $12 \mathrm{~h}$. The animals were provided with drinking water and chow ad libitum. The different chows were provided by Grain Silos and Flour mills Organization, Riyadh, Saudi Arabia. The experimental procedures used in this study were in accordance with the National Institute of Health Guide for the core and Use of Laboratory Animals, Institute for Laboratory 
Animal Research. They were also approved by the Ethical Committee of the College of Pharmacy.

\subsection{Sources of Chemicals}

ADP, arachidonic acid and pestilence tetrazole (Sigma-Aldrich, USA), carrageenan and heparin (Fbuka, Germany), calcium chloride and trisodium citrate (BBH, England).

\subsection{Effect on Guinea-Pig Platelets}

In preparation of PRP (platelets rich plasma): we have used a modified procedure similar to the one described by $[11,12]$ for rabbits and rats.

Male albino guinea-pigs (body weight $=600 \mathrm{~g}$ ) were anaesthetized with ether. From each animal, 9 $\mathrm{mL}$ blood was obtained using cardiac puncture and mixed with $1 \mathrm{~mL}$ of $3-6 \% \mathrm{w} / \mathrm{v}$ aqueous trisodium cifrate in seomi-transparent centrifuge tube. The blood was then centrifuged using centrifuge at 1,200 rpm for $8 \mathrm{~min}$. The upper layers (PRPs) were then aspirated and collected in $50 \mathrm{~mL}$ plastic tube which was placed over ice bath. The PRP was then distributed in 0.45 $\mathrm{mL}$ info plastic aggregation cuvettes (XMM). Part of which is stored at $37{ }^{\circ} \mathrm{C}$ in a separated part in the aggregometer. To obtain PPP (platelets poor plasma), part of the PRP ( $3 \mathrm{~mL}$ ) were centrifuged at 3,600 rpm for $20 \mathrm{~min}$. To investigate the effect of the test compound and the platelets aggregation process, each cuvette containing $0.45 \mathrm{~mL}$ PRP 9, was preheated at $37{ }^{\circ} \mathrm{C}$ for a few minutes, then inserted into the aggregation chamber of the aggregometer.

For further 2 minutes and the light transmission through the PRP was calibrated to be zero. The process was repeated using $0.45 \mathrm{~mL}$ aliquot of the PPP and the light transmission through it was considered to be $100 \%$. Then, to investigate the effect of the compound on the aggregation process, each aliquot of the PRP (preheated at $37{ }^{\circ} \mathrm{C}$ in the aggregometer storage chambers (holes), then placed into the aggregation chamber at $37^{\circ} \mathrm{C}$. A small magnetic stirrer is $91 \times 3$ $\mathrm{mm}$ ), was placed carefully into the PRP and the aggregometer and set to give $1,000 \mathrm{rpm}$. The PRP was stirred for 2 minutes and a dose of the aggregating agent-ADP (adenosine diphosphate) was added in 10 $\mathrm{mL}$ volumes to give final concentrations of 5-20 $\mu \mathrm{m}$. After the concentration was produced, only the irreversible aggregation for 4 min was selected. This was usually $10 \mathrm{~mm}$ final concentration in the PRP. The curette was then discarded and this same process was repeated using the aggregating agent AA (arachidonic acid). Thereafter, the ability of the test compound to inhibit ADP or AA-induced aggregation, was then tested as follows. An aliquot of PRP $(0.45 \mathrm{~mL}$ in a plastic cuvette already preheated at $37{ }^{\circ} \mathrm{C}$ for a few minutes was placed in the aggregation chamlber, heated with stirring for 2 minutes and then a specified dose of the test compound was added, the contents of the curette were mixed by stirring for 5 minutes and then the standard dose of either ADP (final concentration 10 $\mu \mathrm{m})$ or AA was added and the magnitude of the induced aggregation was then followed for 4 minutes. All doses of the test compound tested were added to the PRP in a fixed volume of $10 \mu \mathrm{L}$. The effect of the compound on the magnitude of the aggregation of the standard aggregation agent was then observed, measured and the percentage of inhibition of the induced standard aggregation was calculated. The inhibitory dose 50 (ID50) the dose that inhibited 50\% of ADP or AA induced aggregation was then calculated.

To test the effect of the presence high concentrations of calcium ions on the compound induced inhibition of aggregation, PRP was enriched with calcium chloride by addition of $10 \%$ calcium chloride to raise the calcium $\mathrm{Ca}^{+2}$ concentration by 1-2 $\mathrm{mm}$. The anti-aggregatory effect of the compound against ADP or AA-induced aggregation was then re-investigated as described above.

2.4 The Effect of the Test Compound on the Anaes Thetized Rat Blood Pressure and Heart Rate

Male Wistar rats (250 g body weight) were 
prepared for measurement of systemic arterial blood pressure and heart rate as out lined by Ref. [13]. In brief, the rats were anaesthetized with urethans (25\% $\mathrm{w} / \mathrm{v}$ in water) at a dose of $1.25 \mathrm{~g} / \mathrm{kg}$ (i.p.). The right external jugular rein was exposed and accumulated using a polyethylene catheter (1 mm outer diameter, Inpharven INT, Imphardial, Haly). Heparin sodium $1000 \mathrm{U} / \mathrm{kg}$ was then injected (i.v.). The left carotid artery was then exposed and accumulated using a similar catheter but with 0.8 outer diameter. The cannula was then connected to ITT cannon blood pressure transducer filled with trisodium citrate aqueous solution (3-6\% w/v) to prevent blood clotting. The transducer was then connected to a physiograph recording system (mK-1-v-p Narco Bio-Systems). The temperature of the rat was maintained by using an over head tungsten lamp. The different doses of the test compound were administered i.v. in a maximum volume of $0.8 \mathrm{~mL} / \mathrm{kg}$ were administered (10-100 $\mathrm{mg} / \mathrm{kg}$ ). Each dose was flushed in using $0.2 \mathrm{~mL}$ of $0.9 \% \mathrm{w} / \mathrm{v}$ sodium chloride in distilled water. The effect of each dose on the systemic arterial blood pressure was quantified in $\mathrm{mm} \mathrm{Hg}$ by the aid of the pressure collration system bilt in the physiographic coupler No 7179 used to connect the transducer. To examine the influence of the compound on the rats heart rate, the recording speed was increased from $0.05 \mathrm{~cm} / \mathrm{s}$ to $1 \mathrm{~cm} / \mathrm{s}$ for $5-10$ seconds. The changes in the heart rate were quantified as percentage change compared with the normal heart rate before administration of the compound.

\subsection{Effect of Calcium Chloride on the Compound} Induced Changes in the Blood Pressure and Heart Rate

To examine the effect of high doses of calcium chloride on the compound's induced changes in the arterial blood pressure and heart rate, a procedure similar to that described by Ref. [13] was used. For this purpose, sub maximal responses of the compound were initially obtained. The animal was allowed to rest for 10 minutes and then a total dose of calcium chloride equivalent to $2.4 \mathrm{~mL}$ mole/kg was then administered (i.v.) in three portions at intervals of three minutes. Five minutes after the last portion, the sub maximal dose of the compound was administered. The effects obtained were quantified as described above and compared with those effects observed before administration of calcium chloride. The percentage effectiveness of calcium chloride in protecting the animal was then calculated.

\subsection{Effect of the Test Compound on Pentylene Tetrazole-Induced Conulsions in Mice}

To test presence of any potential anti-convulsant activity, different doses of the test compounds were examined against pentylene tetrazole induced convulsions in mice, and for this purpose, a dose of pentylene tetrazole equal to $100 \mathrm{mg} / \mathrm{kg}$ (i.p.) was used to induce convulsion in $25 \mathrm{~g}$ body weight swiss albino mice as described before [14].

To start the experiment, Swiss albino mice were divided into two groups ( $N=6$ animals per group), one group served as control and the other as the test groups. Each mouse in the control group was injected (i.p.) with aqueous pentytene tetrazole $(12.5 \mathrm{mg} / \mathrm{mL})$ in a dose of $100 \mathrm{mg} / \mathrm{kg}$. Each mouse was observed for the time of onset of convulsions, the frequency of convulsions per unit time till death. The death time was also noted. Each mouse in the second, third and fourth group was injected with the test compound in doses of 100, 200 and $400 \mathrm{mg} / \mathrm{kg}$ (I.p.), respectively. Twenty minutes later the same above mentioned dose of pentylene tetrazole was injected (i.p.) and the above three parameter were observed.

\subsection{Effect of the Compound on Thermally-Induced Pain}

To test the presence of any potential anti-non inceptive activity of the test compound, its effect was examined on thermally induced-pain (nociception) using the hot plate $\left(58{ }^{\circ} \mathrm{C}\right)$ method previously 
described for this purpose, mice were divided into four groups ( $N=5$ mice per group). Initially, the reaction time for feeling of pain for every mouse in the four groups, after its placement on the hot plate $\left(58^{\circ} \mathrm{C}\right.$ ), was noted. This reaction time was determined by lifting the forelimbs and glowing or licking them. Thereafter the mice in the four groups were treated with the test compounds in doses of 12.5, 25, 50 and $100 \mathrm{mg} / \mathrm{kg}$ (i.p.), respectively. The reaction time was then measured 15, 30, 45 and 60 minutes following treatment. The time for occurrence of the relative maximum activity (i.e., higher reaction time in seconds) was noted and the ED50 (effective dose 50), i.e., the dose that increased the reaction time by $50 \%$ at this maximum reaction time was calculated.

\subsection{Statistical Analyses}

The values that reported in this study were mean \pm se and have significant differences after different treatments calculated using ANOVA on Paired ' $\mathrm{f}$ ' test as appropriate.

\section{Results}

\subsection{Effect of the Compound on the Guinea-Pig Platelets}

Addition of ADP in a final concentration of $25 \mathrm{~mm}$ or arachidonic acid $(0.15 \mathrm{~mm})$ to the PRP of a guinea-pig induced irreversible platelets aggregation as seen by the increase in light transmission across the PRP and the non-reversibility of the response. For addition of the compound to the PRP in doses at 1000 rpm for $5 \mathrm{~min}$, no change in light transmission was observed, i.e., no aggregation of platelets was observed. However, any of the above doses completely inhibited AA-induced aggregation. Pre-treatment of the platelets with the compound in doses of 1.25 and $2.5 \mathrm{mg} / \mathrm{mL}$ PRP for 5 minutes inhibited ADP-induced aggregation by $45 \pm 3.5 \%$ and $88 \pm 4.3 \%$, respectively $(N=5, P<0.05)$. Figs. $1 \mathrm{a}$ and $1 \mathrm{~b}$ show the effects of $2.5 \mathrm{mg} / \mathrm{mL}$. Elevation of $\mathrm{Ca}^{+2}$ concentration in the PRP by further $2 \mathrm{~mm}$ prevented the antiaggregatory effect of the compound
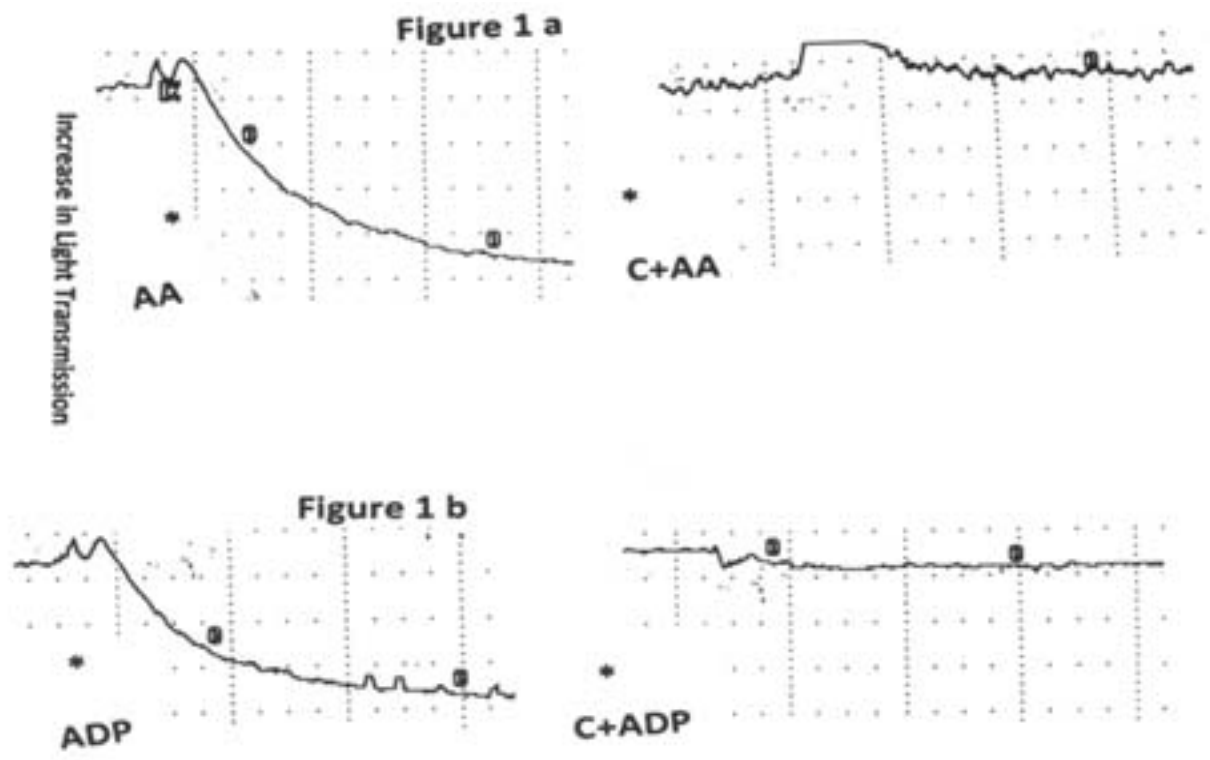

Fig. 1 Effect of the test compound on (a) arachidonic acid-induced and (b) ADP-induced aggregation.

(a): Platelets aggregation in PRP was induced with addition of arachidonic acid (AA, $0.15 \mathrm{~mm}$ final concentration in the PRP) inducing an irreversible platelets aggregation as indicated by the increase in light transmission. Prefreatment of the platelets with 2.5 mg of the compound for 5 min completely inhibited the AA-induced platelet aggregation. (b): Platelets aggregation in PRP was induced with addition of ADP (25 mm, final concentration in the PRP) inducing an irreversible aggregation as indicated by the increase in light transmission. Pretreatment of the platelets with the test compound ( $2.5 \mathrm{mg})$ for 5 minutes inhibited the aggregation by $86 \%$. 
when aggregation was induced by either ADP or AA.

\subsection{Effect of the Compound on the Rat's Arterial} Blood Pressure and Heart Rate

Injection of the compound into the urethane anaesthetized rat in doses of 25 and $50 \mathrm{mg} / \mathrm{kg}$ (i.v.) induced dose-dependent decreases in the arterial blood pressure and the heart rate. The effects on the arterial blood pressure were very fast and more clear than those in the heart rate. The two above doses induced $12 \pm 3$ and $26 \pm 1.9 \mathrm{~mm} \mathrm{Hg}$, respectively $(N=4, P<$
0.05). The corresponding decreases in the heart rate were $6.2 \pm 3.1$ and $10.1 \pm 1.9 \%$, respectively. Treatment of the rats with atropine $1 \mathrm{mg} / \mathrm{kg}$ (i.v.) for 5 minutes did not antagonize the induced changes; however, pretreatment of the rats with aqueous $\mathrm{CaCl}_{2}$ in a total dose of $2.4 \mathrm{~mL}$ mole/kg (I. V) in 3 portions significantly decreases the blood pressure and heart rate. The percentage antagonism was $50 \pm 5 \%$ in magnitude with very rapid reversibility of the induced hypotension. Fig. 2 depicts one of these experiments $(N=4, P<0.01)$

a

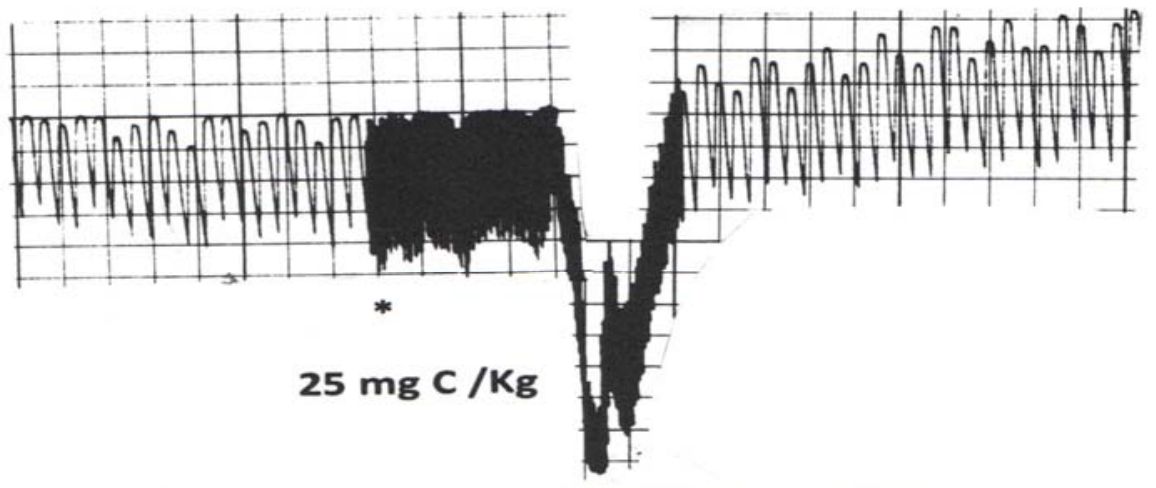

b
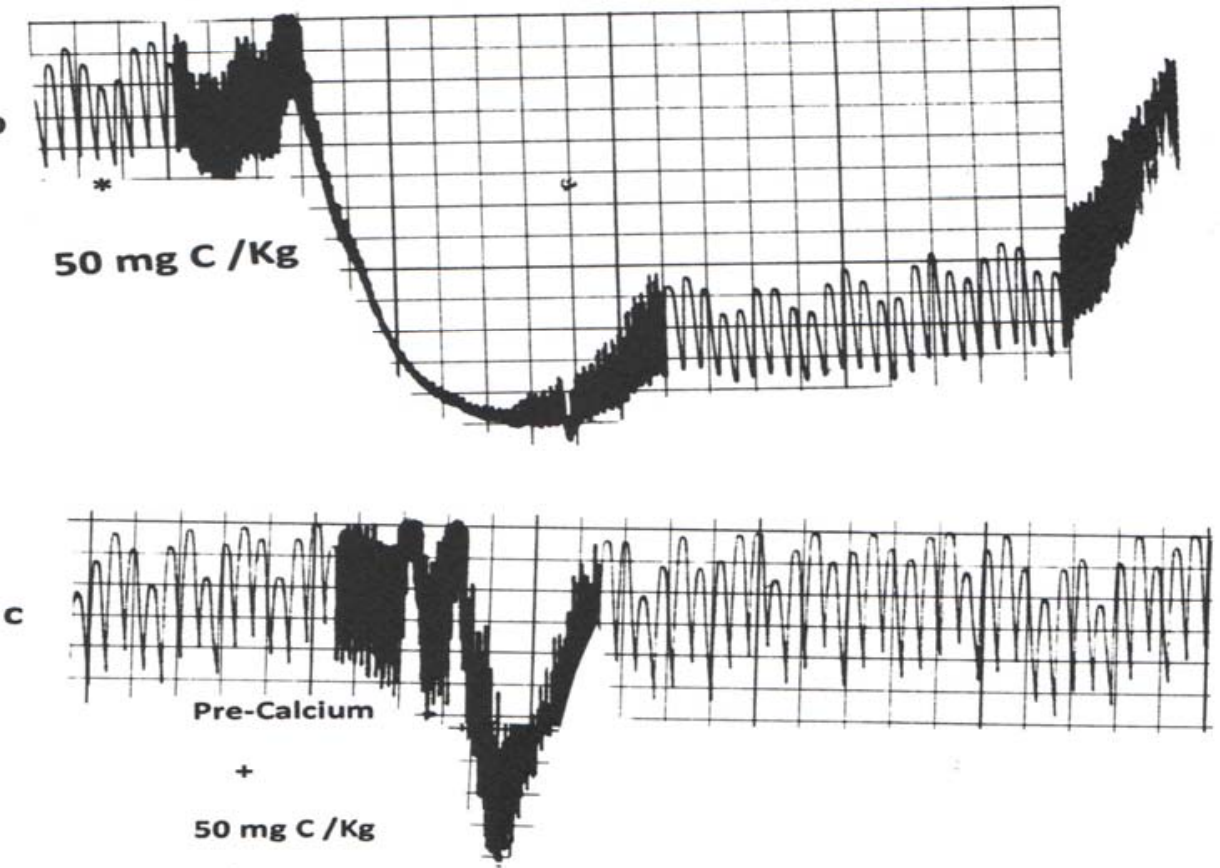

Fig. 2 Effect of the test compound on the rat arterial blood pressure.

Intravenous administration of the test compound into a ure thane-anise etherized rat at doses of $25 \mathrm{and} 50 \mathrm{mg} / \mathrm{kg} \mathrm{induced}$ dose-dependent decreases in the arterial blood pressure (Fig. 2a and c). In this experiment the induced decreases were 15 and $25 \mathrm{~mm}$ $\mathrm{Hg}$. The effect of the higher dose was relatively more sustained than that of the $25 \mathrm{mg} / \mathrm{kg}$ dose. Intravenous administration of calcium inform the chloride salt in a total dose of $2.5 \mathrm{~mm} / \mathrm{kg}$ suppressed the $50 \mathrm{mg} / \mathrm{kg}$ effect by $60 \%$ (figure 2c). 


\subsection{Effect of the Compound on Pentylene} Tetrazole-Induced Convulsions

Injection of swiss albino mice with pentylene tetrazole $100 \mathrm{mg} / \mathrm{kg}$ (i.v.) induced clonic convulsions within 1-2 minutes, following injection, death occurred after 4-5 minutes. In six mice the mean onset of convulsions following (i.p) injection of pentylene tetrazole was $1.2 \pm 0.2$ minutes and the mean death time was $4.7 \pm 0.8$ minutes $(N=6)$. The frequency of the tonic convulsions before death was $15.5 \pm 1.6 / 4$ min. Administration of the compound in doses of 100 and $200 \mathrm{mg} / \mathrm{kg}$ (i.p.) for 20 minutes followed by administration of pentylene tetrazole did not prevent the induced convulsions. Doses of up to $500 \mathrm{mg} / \mathrm{kg}$ were also not effective. However both 100 and 200 $\mathrm{mg} / \mathrm{kg}$ prolonged the onset time of convulsions to 3.1 \pm 0.4 and $8.7 \pm 1.1$ minutes respectively $(P<0.05, N=$ $6)$. The treatment also significantly suppressed the frequency of convulsions to $8.1 \pm 0.9$ per $4 \mathrm{~min}$ following administration of the $200 \mathrm{mg} / \mathrm{kg}$ doses $(P<$ $0.05, N=6$ ). The high dose of $200 \mathrm{mg} / \mathrm{kg}$ also significantly prolonged the death time to $12 \pm 1.6$ minutes $(P<0.05, N=6)$.

\subsection{Effect of the Compound on the Thermally Induced} Pain

Exposure of mice to a hot plate adjusted at a temperature of $58{ }^{\circ} \mathrm{C}$ resulted in rapid feeling of pain expressed as lifting, licking and blowing on the foreleg? The mean reaction time in various mice ranged from 5-6 seconds. Mice were divided into 34 groups ( $N=5$ mice/group). These were administered the compound into doses of $12.525,50$ and $100 \mathrm{mg} / \mathrm{kg}$ (i.p.) and minutes later, the animals were exposed again to the hot plate. And the reaction times were examined 15, 30, 45 and 60 minutes following administration of the compound. There were dose and time related increases in the reaction time. The maximum increase was noted 30 minutes after administration of the compound. The ED50 was calculated 30 minutes after administration of the compound. It was found to be $85.7 \pm 6.3 \mathrm{mg} / \mathrm{kg}(N=5)$.

\section{Discussion}

The results of this study revealed other new actions for the compound 1(z)-2 (hydroxymethyl)-dodec-1-ene-1,3-diol in addition to the previously known action of protection against $\mathrm{CaCl}_{2}$ induced dysrhythmia in mice [2]. As shown in the results section these included a selective platelet anti-aggregatory activity against arachidonic acid, a vascular relaxant activity as reflected by the decrease in the rat's arterial blood pressure, a potential mild anti-covulsant activity and an anti-nociceptive activity in mice. Attempts were made to elucidate the mechanisms of action of two of the upper newly-observed actions. In both platelets and the arterial blood pressure a clear potent ion emerged as blockade of calcium channels, most probably the l-type. This conclusion was derived from the ability of reversing the observed actions by elevating the extracellular calcium levels by administration of exogenous calcium chloride. This mechanism is in accord with the previously observed cardiac protection against calcium chloride-induced disturbances in mice [2].

Regarding the anti-nociceptive and the anti-convulsant activities, no attempts at this time were made to elucidate the underlying mechanisms. However, conjectures are possible. Generally, pain is felt following a specific pathway from the site it started, through the substantial gelationsa inside the dorsal horn of the spinal cord and up to the pain centre in the thalamus and its integration in the sensory cortex [15].

This pathway always involves release of peripheral pain nociceptive sensitizers such as prostaglandins, e.g., $\mathrm{PGE}_{2}$ and $\mathrm{PGI}_{2}[16]$.

And release of pain neurotransmitters from the primary afferent nerves within the spinal substantial gelatinosa which include substance $\mathrm{P}$, neurobinins, 
glutamic and spartic acid and bombesin [17].

Such pain neurotransmictters are regulated or even inhibited by some spinal and supraspinal mechanisms resulting in release of endogenous opioids such as enkephalins and dynorfin, GABA, glycine, 5-HT and NA [17]. Thus, drugs that suppress pain can act at any site to suppress release of pain sensitizers and neurotransmitters to stimulate release of endogenous inhibitors or activate their receptors at the terminals of the primary afferents. Thus, the test compound can act at any of their sites. Further experiments can revere the actual mechanisms. In this connection, one can inquire at the present time to an inhibitory effect on peripheral pain sensitizers, e.g., $\mathrm{PGE}_{2}$ and $\mathrm{PGI}_{2}$ (prostlyclin). This can be deduced from the inhibitory effect of the compound as an AA induced platelets aggregation. It is a well-established fact that AA-induced platelets aggregation is mediated via synthesis of $\mathrm{TXA}_{2}$ resulting from the activities of COX-1 and $\mathrm{TAX}_{2}$ syntheses enzymes [3].

Indeed, inhibition of AA-induced aggregation implies that at least part of COX-1 enzyme inhibition as a $\mathrm{TXA}_{2}$ receptor blockades on $\mathrm{TXA}_{2}$ synthesis inhibition.

\section{Conclusion}

Regarding pentylene tetrazole-induced convulsions various mechanisms have been involved. These ranged from an increase in the availability of brain stimulants, e.g., glutamate inhibition of GABA activity and inhibition of 5-HT, all of which involve the common mediator calcium ions [18]. Thus, one is inclined to point to an antagonism to calcium as an involved mechanism in the observed prolonged, a hen of both the onset and time of death following treatment with the compound. Definitely, these proposed conjured mechanisms need for their studies to pinpoint the actually involved ones. Only future experiments can unravel those issues.

\section{References}

[1] Al-Dosary, M. M., and El-Tahir, K. E. H. 2012.
"Pharmacological Actions of Integument Extracts of Red Palm Weeril Rhynchophorus ferragineus in Albinomice." Agric. Biol. J. N. Am. 3 (2): 49-56.

[2] Al-Dosary, M. M., and El-Tahir, K. E. H. 2013. “(Iz)-2-(Hydroxymethyl)-Dodec-1-Ene-1,3-Diol Isolated from Integument of the Red Plam Weevil Rhynhophorus ferrugineus for Treatment of Calcium-Induced Dystthythmic.” WULFENIA Journal 20 (10): 307-57.

[3] Agardi, E., Tremolie, E., Colombo, C., and Galli, C. 1978. "Influence of Short Term Dietary Supplementation of Different Lipids on Aggregation and Arachidonic Acid Metabolism in Rabbit Platelets.” Prostaglandins 16 (6): 973-84.

[4] Rink, T. J., and Sage, S. O. 1990. "Calcium Signaling in Human Platelets.” Annu. Rev. Physiol. 52: 431-49.

[5] Block, R. C., Chin, C. W., Wu, W., and Zbuzek, V. K. 1993. "Nicotine Induced Analgesia in Rats: The Role of Calcium and Diversity of Responders and Non-responders.” Life Sci. 53 (12): PL195-200.

[6] Smith, F. L., and Stevens, D. L. 1995. "Calcium Modulatim of Morphine Analgesia Role of Calcium Channels and Intracellular Pool Colcum.” J. Pharmacol. Exptl. Ther. 272: 290-9.

[7] Zamponi, G. W., Lewis, R. J., Todorovic, M., Arneric, S. P., and Snutch, T. P. 2009. "Role of Volfage-Gated Colcum Channels in Ascending Pain Pathways.” Brain Res. Rev. 60: 84-9.

[8] Meyer, F. B., Anderson, R. E., and Sundt, T. M. J. R. 1987. "Suppression of Pentylene Tetrazole Seizures by Oral Administration of a Dihydropyridine Calcium Antagonist.” Epilepsia 28: 409-14.

[9] Shitak, R., Sahai, A. K., Hota, D., and Chakrabarti, A. 2007. "Evaluation of the Modulatory Role of Nimodipine in Seizures Induced by Kainic Acid and Pentylene Tetrazole in Mice Methods Findings.” Expt. Clin Pharmacol. 29: 11-7.

[10] Kaur, M., and Goel, R. K. 2011. “Anticonvulsant Activity of Boerhaavia diffusa: Plausible Role of Calcium Channel Antagonism.” Evidence-Based Complementary and AHVF. Med. 2011: 1-7.

[11] El-Ttahir, K. E. H., and Willams, K. I. 1980. "Factors Affecting Prostacy Chin Formation by the Rat Pregnant Myometrium.” Br. J. pharmacol. 71: 641-7.

[12] El-Tahir, K. E., Ali, A. E., Abu- Nasif, M. A., Ageel, A. M., and Gabrarim, E. A. 1986. "The Influence of Oral Hypoglycaemic Sulfonyl Ureas on Prostacyclin Release by the Rat Thoracic Aorta.” Archir. Int. Pharmacodyn. Ther. 283 (1): 134-40.

[13] El-Tahir, K. E., El-Naser, M. S. A., Ageel, A. M., El-Obeid, H. A., and Al-Rashood, K. A. 1991. "Cardiovascular Depressant Effects of N-Methyl- and N-Isobutyl-1,2-Diphenyl Ethanolamines: Elucidation of 
the Mechanisms of Action.” Archiv. int. pharmacodyn. Ther. 309: 88-102.

[14] El-Azab, A. S., and El-Tahir, K. E. H. 2012. "Synthesis and Anticonvulsant Evaluation of Some New 2,3,8-Trisubstituted-4(3H)-Quinazoline Derivatives.” Bioorganic \& Medicinal Chemistry Letters 22 (1) 327-33.

[15] Basbaum, A. L., and Fields, H. L. 1984. "Endogenous Pain Control Systems: Brain and Spinal Pathways and Endorphin Circuit.” Annu. Rev. Neurosci 7: 309-38.
[16] Raja, S. N., Meyen, R. A., and Complelle, J. N. 1988. "Peripheral Mechanisms of Somatic Pain." Anesthesiology 68 (4): 571-90.

[17] Yakash, T. L. 1988. “Central Nervous System Mechanisms of Pain and Analgesia.” Cancer Surveys 7: 5-28.

[18] Rogawski, M. A. 2006. "Diverse Mechanisms of Antiepileptic Drugs in the Development Pipeline." Epilepsy. Res. 69 (3) 273-94. 